\title{
A General Copper-based Photoredox Catalyst for Organic Synthesis: Scope, Application in Natural Product Synthesis and Mechanistic Insights
}

\author{
Christopher Deldaele ${ }^{\mathrm{a}}$, Bastien Micheleta, Hajar Baguia ${ }^{\mathrm{a}}$, Sofia Kajouj ${ }^{\mathrm{b}}$, Eugénie Romero ${ }^{\mathrm{a}}$, Cécile \\ Moucheron $^{\mathrm{b}}$, and Gwilherm Evano ${ }^{\star a}$
}

\begin{abstract}
Organic transformations can broadly be classified into four categories including cationic, anionic, pericyclic and radical reactions. While the last category has been known for decades to provide remarkably efficient synthetic pathways, it has long been hampered by the need for toxic reagents, which considerably limited its impact on chemical synthesis. This situation has come to an end with the introduction of new concepts for the generation of radical species, photoredox catalysis - which simply relies on the use of a catalyst that can be activated upon visible light irradiation - certainly being the most efficient one. The state-of-the-art catalysts mostly rely on the use of ruthenium and iridium complexes and organic dyes, which still considerably limits their broad implementation in chemical processes: alternative readily available catalysts based on inexpensive, environmentally benign base metals are therefore strongly needed. Furthermore, expanding the toolbox of methods based on photoredox catalysis will facilitate the discovery of new light-mediated transformations. This article details the use of a simple copper complex which, upon activation with blue light, can initiate a broad range of radical reactions.
\end{abstract}

Keywords: Copper $(0) \cdot$ Copper catalysis $\cdot$ Natural products $\cdot$ Photoredox catalysis $\cdot$ Radicals

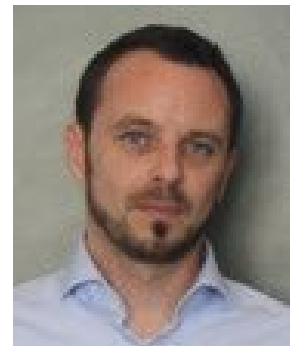

Gwilherm Evano was born in Paris in 1977 and studied chemistry at the Ecole Normale Supérieure. He received his $\mathrm{PhD}$ from the Université Pierre et Marie Curie in 2002 under the supervision of Profs. François Couty and Claude Agami. After postdoctoral studies with Prof. James S. Panek, he joined the CNRS as associate professor in 2004 He then moved to the Universite libre de Bruxelles, where he became the head of the Laboratory of Organic Chemistry in 2012. His research program currently focuses on natural/bioactive product synthesis, copper catalysis, organometallic chemistry and on the chemistry of heteroatom-substituted alkynes and reactive intermediates.

\footnotetext{
${ }^{\star}$ Correspondence: Prof. G. Evano ${ }^{a}$ E-mail: gevano@ulb.ac.be aLaboratoire de Chimie Organique Service de Chimie et PhysicoChimie Organiques Université libre de Bruxelles (ULB) Avenue F. D. Roosevelt 50, CP160/06, 1050 Brussels, Belgium

'Laboratoire de Chimie Organique et Photochimie Service de Chimie et PhysicoChimie Organiques Université libre de Bruxelles (ULB)

Avenue F. D. Roosevelt 50, CP160/08, 1050 Brussels, Belgium
}

\section{The ABC of Photoredox Catalysis and Copper Complexes}

Photocatalysis is the acceleration of a chemical reaction by the combination of a catalyst and a source of light. ${ }^{[1]}$ This broad field, which was actually already mentioned by Plotnikow in his 1936 book entitled 'Allgemeine Photochemie',[2] really began with the pioneering contributions of Fujishima and Honda, who reported in 1972 the photolysis of water with a $\mathrm{TiO}_{2}$ electrode in a photoelectrochemical cell, ${ }^{[3]}$ and the discovery of the photocatalysis of organic reactions by Pac and Deronzier in the early 1980 s. ${ }^{[4]}$

Photocatalysis, more properly termed 'photoredox catalysis' since the photons are nothing close to 'catalysts' in such processes, has seen growing interest recently and is today an especially active area of chemical research, notably due to its applications in fields such as medicine, chemical synthesis, material science or environmental chemistry and to the number of chemical processes of utmost importance that can be developed, performed or optimized based on this concept. These include not only the reactions of small molecules such as $\mathrm{H}_{2} \mathrm{O}$ (water splitting) ${ }^{[5]}$ or $\mathrm{CO}_{2}$ (forming solar fuels)[6] but also organic substrates, which is especially convenient and remarkably useful either for the degradation of organic contaminants (e.g. for water decontamination or self-cleaning materials) and for the generation of radical species under mild and environmentally friendly conditions, which has had a deep impact in organic synthesis and clearly contributed to the recent revival of radical chemistry. ${ }^{[7]}$ Indeed, while the generation of radical species typically relies on the use of toxic and/or hazardous reagents such as tin derivatives and peroxides, they can now be readily generated by irradiation with light in the presence of a photoredox catalyst, which is much more practical and enabled the development of remarkably efficient and innovative processes. Growing environmental constraints and regulations have also clearly contributed to the attractiveness of organic photoredox catalysis, from both academic and industrial perspectives, since it enables the generation of a range of radical species under mild, safe and environmentally-friendly conditions.

Due to the broad range of applications of modern photocatalysis, the number of catalytic systems reported to date is impressive. They can be primarily classified according to their homogeneous or heterogeneous nature and the use of one over another strongly depends on the area of application. Heterogeneous photocatalysts - titanium dioxide being one of the most popular - are for example commonly used in photocatalytic reduction of carbon dioxide and water splitting, while homo- 
geneous ones are usually preferred and/or more suitable for organic photocatalysis.

Homogeneous photocatalysis has been largely dominated by ruthenium and iridium complexes whose main features encompass strong absorption in the visible, high oxidation and reduction potentials, intense luminescence and long-lived excited states (typically in hundreds of ns or in the $\mu$ s range). ${ }^{[7]}$ The main alternatives to the use of these photocatalysts mostly rely on the use of organic dyes ${ }^{[8]}$ or photoactivatable gold complexes ${ }^{[9]}$ that were introduced recently. Limitations however still remain with all these photocatalysts, notably in terms of availability, price and applications.

In sharp contrast, much less attention has been devoted to copper complexes in photoredox catalysis, ${ }^{[10]}$ despite their strong potential not only as cheaper catalysts but also for the activation of a broader range of substrates opening new opportunities in light-mediated chemical transformations. The use of copper(I)-phenanthroline complexes as alternative to ruthenium(II)- polypyridines actually dates back to the late 1970s when McMillin reported, in a remarkable contribution to this field, that bis(2,9-dimethyl-1,10-phenanthroline) copper(I) tetrafluoroborate, $\mathrm{Cu}(\mathrm{dmp})_{2} \mathrm{BF}_{4}$, "has a rather low-lying metal-to-ligand charge-transfer excited state and could be expected to participate in some interesting photoredox chemistry". ${ }^{[11]}$ Following pioneering studies by the Kutal, ${ }^{[12]}$ Mitani ${ }^{[13]}$ and Sauvage ${ }^{[14]}$ groups next demonstrated the potential of copper(I) complexes for the photoredox catalysis of organic transformations, quite simple ones however. While these complexes have remained attractive among inorganic photochemists, ${ }^{[15]}$ they have been scarcely used in photoredox transformations, which can mostly be attributed to their short-lived excited states. They have therefore been considered to be poor alternatives to ruthenium and iridium complexes, even if recent contributions have clearly reinvigorated this area and further demonstrated the remarkable potential of copper complexes as photocatalysts, ${ }^{[16]}$ their use in organic synthesis still mostly being limited to activated substrates, however.

In order to address this limitation and based on our long-standing interest in copper catalysis, ${ }^{[17]}$ we recently reported a general and broadly applicable copper-based photoredox catalyst, [(DPEPhos)(bcp)Cu]PF, for photoredox transformations of organic halides. ${ }^{[18]}$ We now report a full account on this catalyst, its use for the catalysis of a range of radical processes and for the synthesis of biologically relevant targets ${ }^{[19]}$ as well as mechanistic insights into the photocatalytic cycles together with a comparison with other photoredox catalysts.

\section{2. [(DPEPhos)(bcp)Cu]PF : an Optimal Copper-based Photoredox Catalysis}

\subsection{Screening Copper Complexes in Search for an Optimal Copper- based Photoredox Catalyst}

We initiated our studies by screening a series of homoleptic and heteroleptic

Model Reaction for Screening Copper Complexes

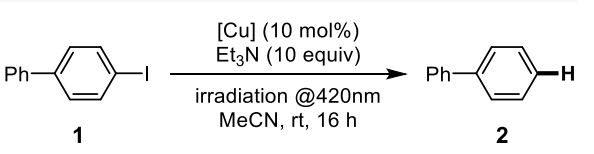

Copper(I) Complexes Screened

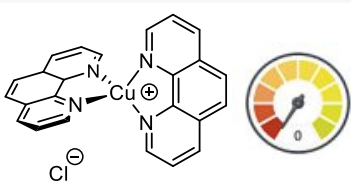

$\left[(\text { phen })_{2} \mathrm{Cu}\right] \mathrm{Cl}$

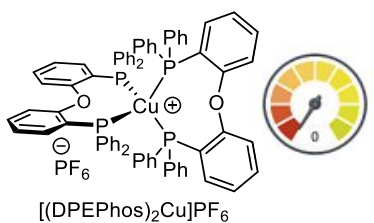

[(DPEPhos $\left.)_{2} \mathrm{Cu}\right] \mathrm{PF} 6$

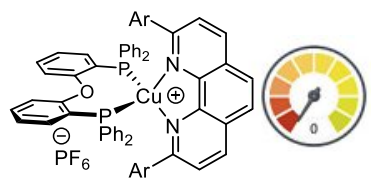

[(DPEPhos)(dap)Cu]PF 6 $\left(\mathrm{Ar}=4-\mathrm{MeO}-\mathrm{C}_{6} \mathrm{H}_{4}\right)$

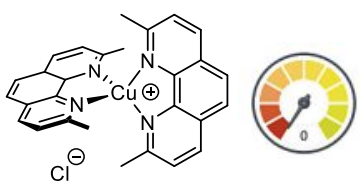

$\left[(\mathrm{dmp})_{2} \mathrm{Cu}\right] \mathrm{Cl}$

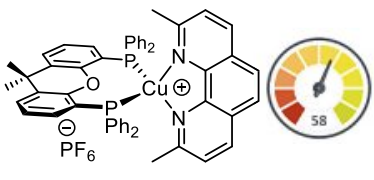

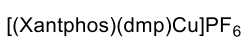

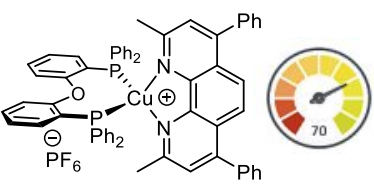

[(DPEPhos)(bcp)Cu]PF 6

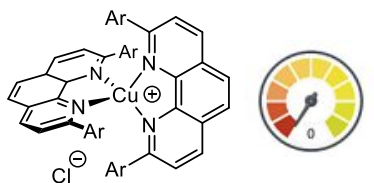

$\left[(\text { dap })_{2} \mathrm{Cu}\right] \mathrm{Cl}$ $\left(\mathrm{Ar}=4-\mathrm{MeO}-\mathrm{C}_{6} \mathrm{H}_{4}\right.$

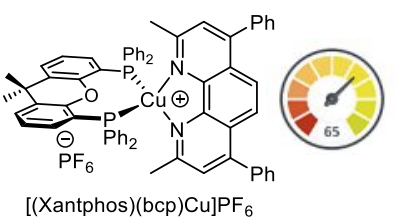

$[($ Xantphos $)(\mathrm{bcp}) \mathrm{Cu}] \mathrm{PF}_{6}$

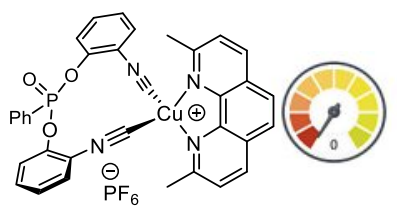

$[($ binc $)(\mathrm{dmp}) \mathrm{Cu}] \mathrm{PF}_{6}$

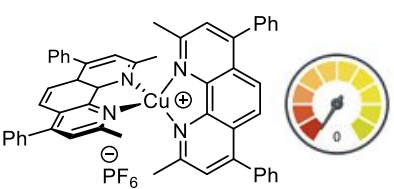

$\left[(\mathrm{bcp})_{2} \mathrm{Cu}\right] \mathrm{PF}_{6}$

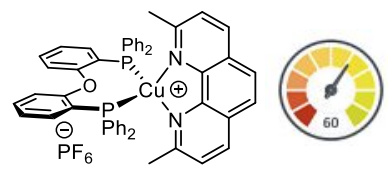

[(DPEPhos)(dmp)Cu]PF 6
Sacrificial Reductants / Additives Evaluated with [(DPEPhos)(bcp)Cu]PF 6
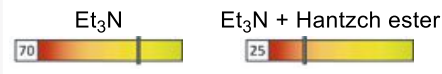

$\mathrm{Et}_{3} \mathrm{~N}+\mathrm{HCO}_{2} \mathrm{H}$

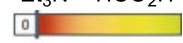

$\mathrm{Et}_{3} \mathrm{~N}+\mathrm{NaAsc}$

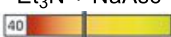

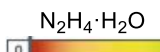

$\mathrm{PhNHNH}_{2}$
$\mathrm{Et}_{3} \mathrm{~N}+\mathrm{Et}_{3} \mathrm{SiH}$

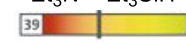

Optimized Conditions with [(DPEPhos)(bcp)Cu]PF 6

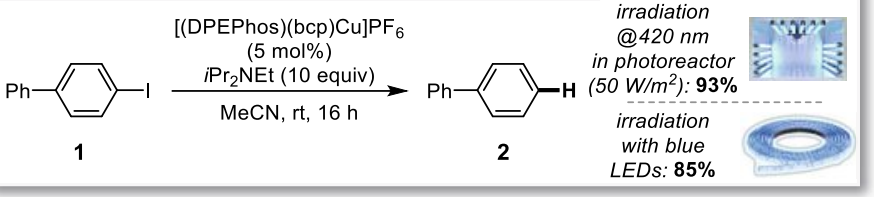

Fig. 1. Optimization of the copper-based photoredox catalyst and reaction conditions. 
copper(I) complexes for the model reduction of biphenyliodide 1 using excess triethylamine as the sacrificial reductant in acetonitrile at room temperature under irradiation at $420 \mathrm{~nm}$ (Fig. 1). Despite the obvious limited synthetic usefulness of this transformation, it was selected due to the well-known difficult activation of a $\mathrm{C}\left(\mathrm{sp}^{2}\right)-\mathrm{I}$ bond, the redox potential for the reduction of iodobenzene being $-1.91 \mathrm{~V}$ vs SCE.[16a] While all homoleptic complexes of phenanthroline and diphosphine derivatives were found to be inefficient, heteroleptic complexes ${ }^{[20]}$ combining both one electrondeficient phenanthroline and one electronrich chelating diphosphine ${ }^{[16 c, d, 21]}$ turned out to be much more efficient, [(DPEPhos) (bcp) $\mathrm{Cu}] \mathrm{PF}_{6}$, whose efficiency as a photosensitizer for the photocatalytic reduction of water ${ }^{[16 \mathrm{~d}]}$ and carbon dioxide ${ }^{[21 \mathrm{~b}]}$ had been previously demonstrated, displaying the highest efficiency. Replacing the diphosphine by a bis(isonitrile) ${ }^{[16 \mathrm{k}]}$ resulted in a total lack of activity.

Further optimization based on the nature of the sacrificial reductant revealed that the model reduction was best performed using Hünig's base, which in addition enabled reducing the catalyst loading to 5 mol\%. Under these conditions, biphenyl 2 resulting from the copper-catalyzed photoinduced reduction of $\mathbf{1}$ could be obtained in $93 \%$ yield. Importantly, a photoreactor is not required for this transformation since simple commercially available blue LED strips can be used with a similar efficiency.

\subsection{Multigram-scale Synthesis of [(DPEPhos)(bcp)Cu]PF ${ }_{6}$ and Evaluation of its Stability}

Before moving to a detailed study of the potential of [(DPEPhos)(bcp)Cu]PF as a photoredox catalyst for organic synthesis, we first addressed its synthesis on a multigram scale, an easy and user-friendly procedure being a prerequisite for the development of a practical catalyst. Its synthesis could be readily performed on a 10 -gram scale by simply successively adding 1 equivalent of DPEPhos and 1 equivalent of bathocuproine to a dichloromethane solution of tetrakisacetonitrile copper(I) hexafluorophosphate, [(DPEPhos)(bcp)Cu]PF being simply isolated in an analytically pure form by precipitation as a bright yellow solid (Fig. 2). Conveniently, it is not especially sensitive to water or oxygen and can therefore be easily handled; as most photoredox catalysts, it is however preferentially stored away from light!

The main problem associated to heteroleptic copper complexes being their equilibrium with the corresponding homoleptic complexes, we next addressed its stability. In the absence of light, not even a trace of the homoleptic complexes could be detected after a day, minor amounts of catalyti- cally inactive homoleptic complexes being detected upon irradiation at $420 \mathrm{~nm}$ ( $\mathrm{ca}$. $20 \%$ after a day), Fig. 2.

Having in hand a robust procedure for the synthesis of [(DPEPhos)(bcp)Cu]PF on a multigram scale and having addressed potential problems associated to its stability, its ability to act as a photoredox catalyst for organic synthesis was next evaluated. Representative and selected results will be overviewed in the next section. substrate scope for the photoinduced activation of carbon-halogen bonds with [(DPEPhos)(bcp)Cu]PF $\mathrm{PF}_{6}$ that compares well with other photoredox catalysts commonly used. All kind of aryl iodides can indeed be activated, ${ }^{[22]}$ regardless of their substitution pattern and electronic properties, upon reaction with $5 \mathrm{~mol} \%$ of the catalyst in the presence of excess diisopropylethylamine in acetonitrile at room temperature. Notably, the reaction was found

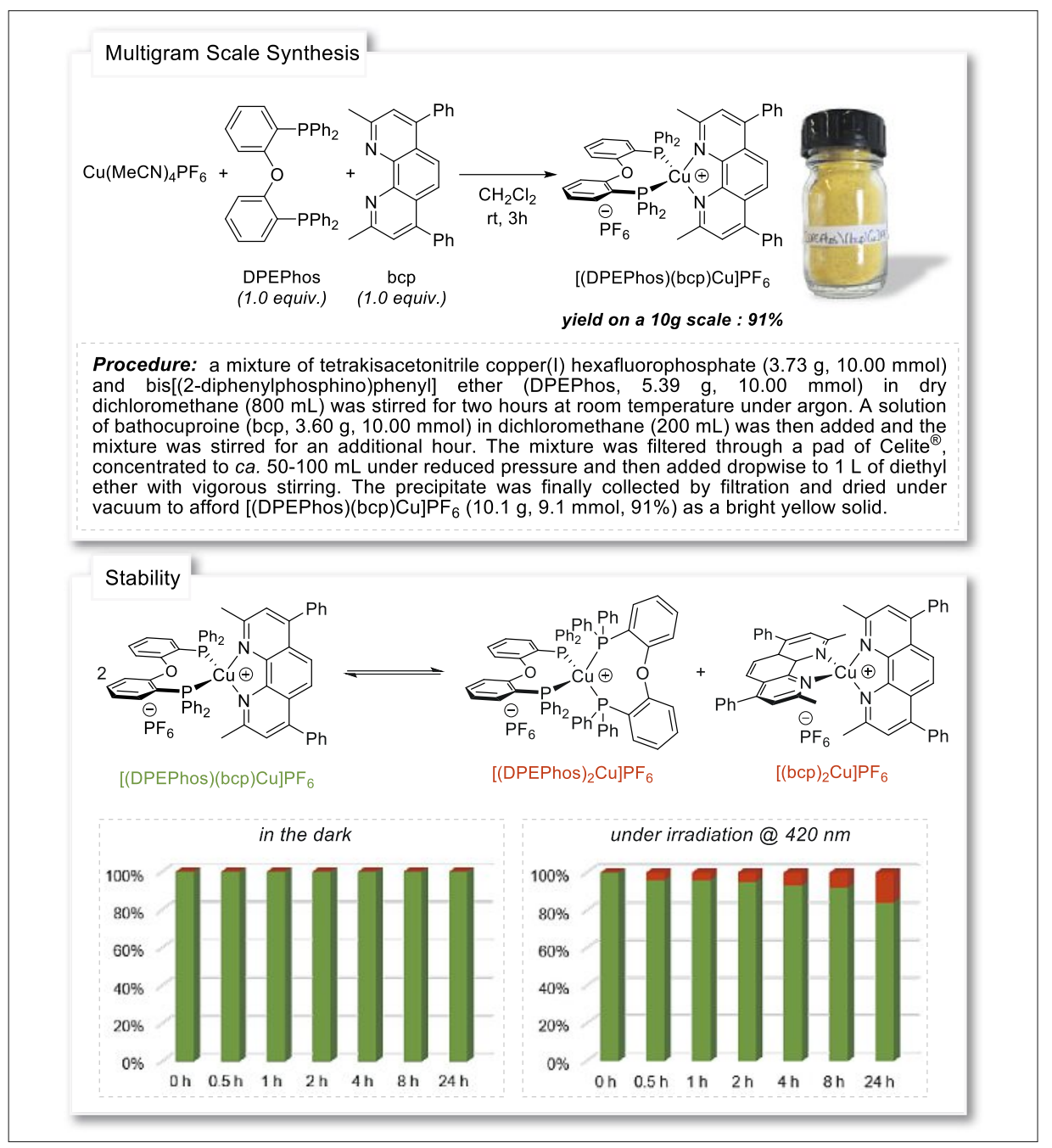

Fig. 2. Multigram-scale synthesis of [(DPEPhos)(bcp)Cu $\mathrm{PF}_{6}$ and stability.

\section{3. [(DPEPhos)(bcp)Cu]PF : a Remarkably Efficient Photoredox Catalyst}

In order to have a clear idea of the substrates that could be activated with [(DPEPhos)(bcp)Cu]PF ${ }_{6}$ and next move to its use for the catalysis of radical reactions, we first evaluated the reduction of a broad range of organic halides with representative electronic and steric properties.

\subsection{Range of Substrates Activatable with [(DPEPhos)(bcp)Cu]PF}

Results from this study are collected in Fig. 3: overall, they reveal a rather broad to be compatible with a range of functional groups, including a boronate, and could also be extended to heteroaryl iodides. The activation of the $\mathrm{C}\left(\mathrm{sp}^{2}\right)-\mathrm{Br}$ bond in aryl bromides, which is known to be more difficult due to the slow $\mathrm{C}-\mathrm{Br}$ bond cleavage kinetics, [22a,23] was found to be more sensitive to the electronic nature of the starting material: while electron-poor aryl bromides were found to be excellent substrates that were readily reduced, electronrich aryl bromides were mostly recovered at the end of the reaction. As for aryl chlorides, whose reduction by photoredox catalysis is still an unsolved challenge, they were shown to be poor reaction partners. 
Alkenyl iodides were also shown to be viable substrates: while their reduction was shown to proceed with moderate efficiency only despite full conversions, their smooth activation by [(DPEPhos)(bcp)Cu]PF offers interesting perspectives for their use in intramolecular copper-catalyzed photoinduced radical processes. Gratifyingly, both alkyl iodides and bromides were shown to be excellent substrates readily activated under the optimized reaction conditions.

\subsection{Copper-catalyzed,}

\section{Photoinduced Radical Cyclizations}

Having a clear idea of the substrates that can be activated upon irradiation in the presence of [(DPEPhos)(bcp)Cu] $\mathrm{PF}_{6}$, its synthetic usefulness in radical cyclizations was next demonstrated, the main idea being to highlight both its efficiency and its potential as an alternative to more standard techniques for the generation of radical species as well as to other photoredox catalysts typically used. An overview of the use of [(DPEPhos)(bcp)Cu]PF for the catalysis of radical cyclizations can be found in Fig. 4. The simple reductive radical cyclization from aryl iodides $\mathbf{3}$ possessing a suitably placed alkene proceeded smoothly to afford, depending on the nature of the tether $\mathrm{Y}$, the corresponding polysubstituted indolines $(\mathbf{4 a}-\mathbf{h}),{ }^{[9 a, 22 a, b]}$ dihydrobenzofurans $(\mathbf{4 i}-\mathbf{l})^{[9 a, 22 a, c, d]}$ and indanes $(\mathbf{4 m}-\mathbf{p})$. The use of $10 \mathrm{~mol} \%$ of the catalyst was found to be
Fig. 3. Evaluation of the range of substrates activatable with [(DPEPhos)(bcp)Cu]PF . in a photoreactor was shown to be slightly superior to the use of blue LEDs. The remarkably mild reaction conditions tolerate a range of substituents on both the aromatic

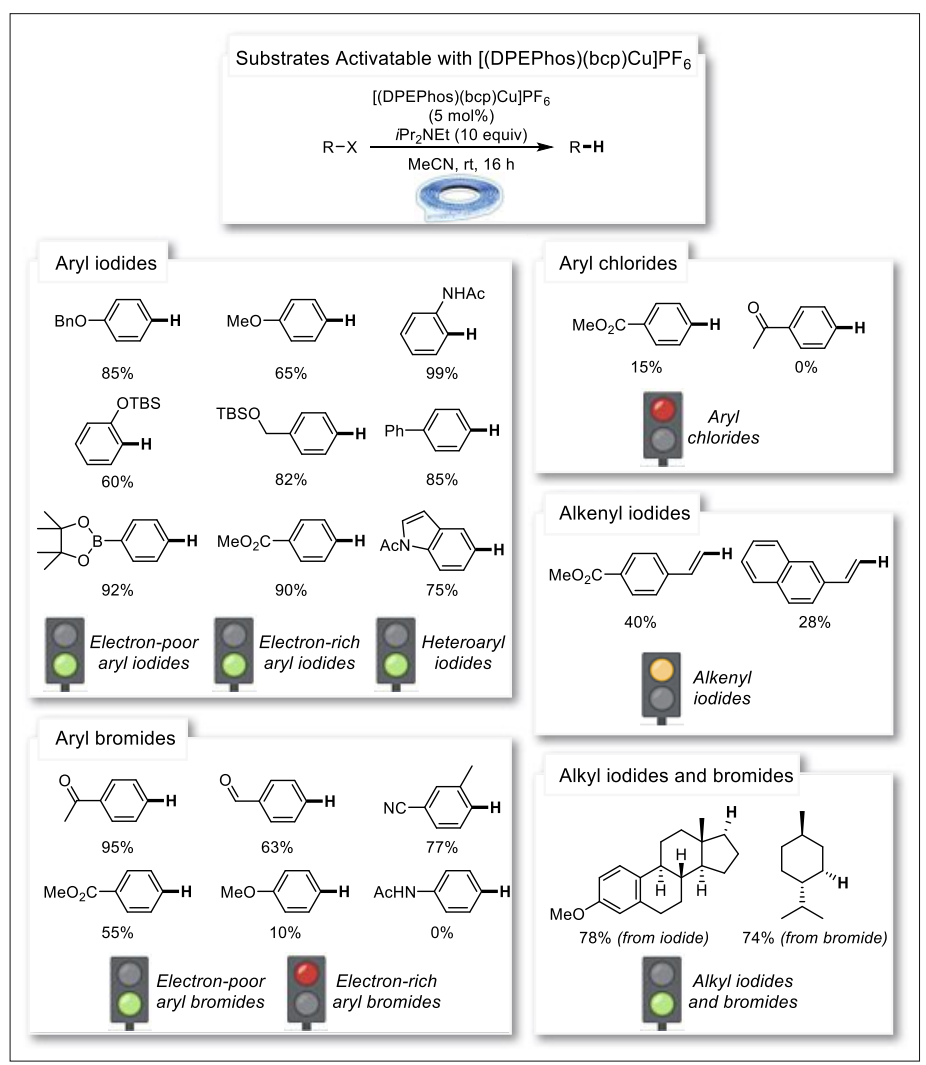

ring, the tether and the alkene. Importantly, the yields of the cyclized products compared well with the ones obtained through other procedures in which the radical species were generated through classical tech-

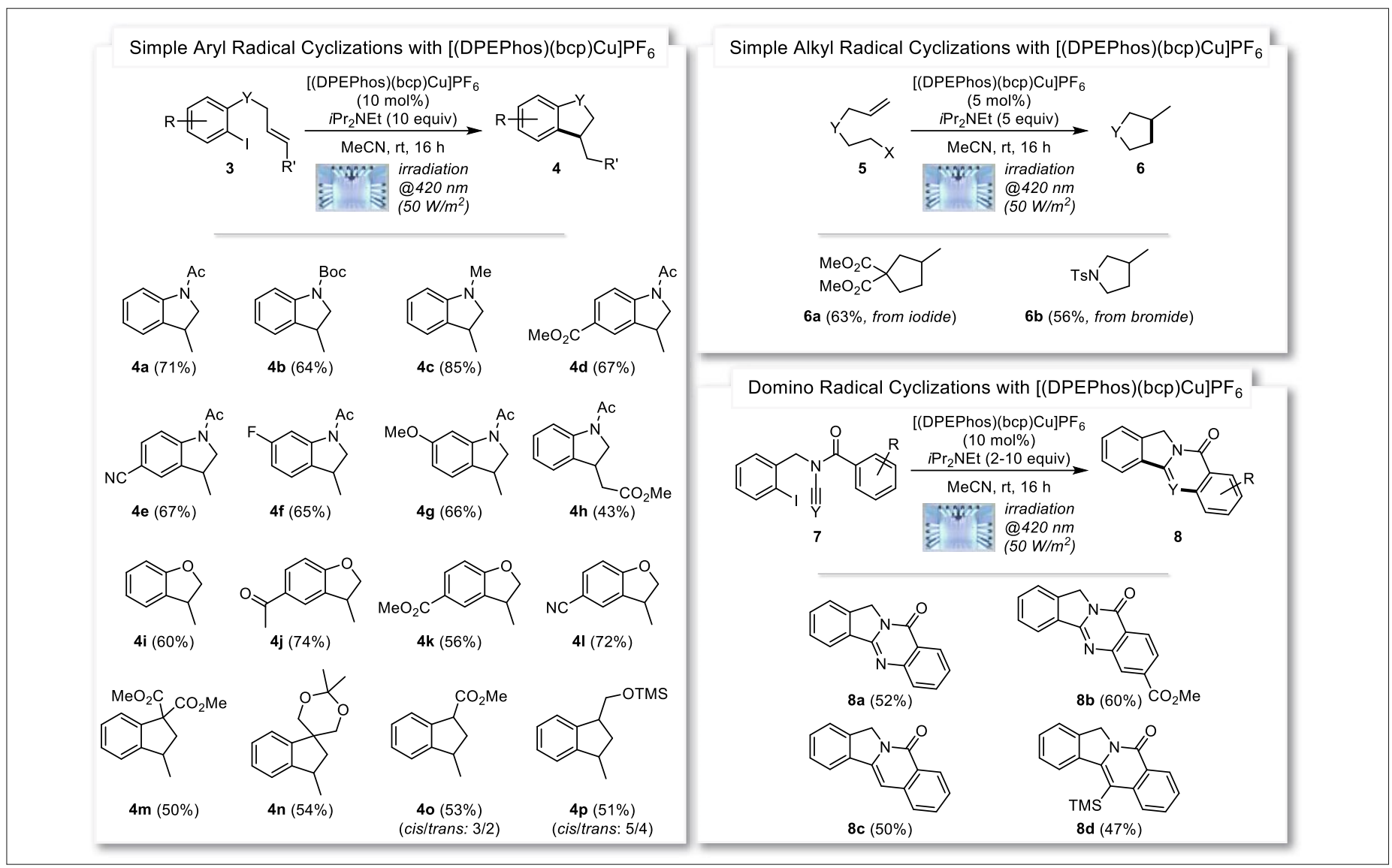

Fig. 4. Copper-catalyzed photoredox radical cyclizations. 
niques or with other photocatalysts, clearly demonstrating the synthetic usefulness and broad applicability of [(DPEPhos)(bcp)Cu] $\mathrm{PF}_{6}$ as a catalyst for photoredox transformations of aryl halides.

Radical cyclizations can also be promoted from alkyl halides $\mathbf{5}$, as highlighted with the cyclization to cyclopentane $\mathbf{6} \mathbf{a}$ and pyrrolidine $\mathbf{6 b}$ derivatives obtained in reasonable yields with 5 mol\% of [(DPEPhos) (bcp)Cu] $\mathrm{PF}_{6}$, provided that the amount of the sacrificial reductant was decreased to minimize the competing reduction of the starting material.

Finally, the efficiency of this approach was further highlighted with domino radical cyclizations from readily available $N$-benzoyl- $N$-(o-iodobenzyl)-cyanamides 7 $(\mathrm{Y}=\mathrm{N})$ and ynamines $7(\mathrm{Y}=\mathrm{CR}){ }^{[19]}$ While the cyclization of such substrates to the corresponding complex tetracyclic molecular scaffolds $\mathbf{8}$ was previously reported under tin-mediated conditions ${ }^{[24]}$ and by photoredox activation using the highly reducing and expensive iridium catalyst $f a c-\operatorname{Ir}(\mathrm{ppy})_{3},{ }^{, 25]}$ we could demonstrate that [(DPEPhos) (bcp) $\mathrm{Cu}] \mathrm{PF}_{6}$ was a viable and efficient alternative. Indeed, upon reaction with 10 mol\% of this photoredox catalyst in the presence of two equivalents of Hünig's base from cyanamides and ten from ynamides under irradiation at $420 \mathrm{~nm}$ in acetonitrile at room temperature for 16 hours, the cyclization was shown to proceed efficiently, smoothly affording the corresponding cyclized products $\mathbf{8}$ resulting from a domino radical cyclization in fair to good yields and with efficiencies that nicely compare with previously reported procedures.

\subsection{One Step Further: Copper- catalyzed, Photoinduced Direct C-H Arylation of Pyrroles and Electron- rich Arenes with Aryl Halides}

Having confirmed the broad applicability of [(DPEPhos)(bcp)Cu] $\mathrm{PF}_{6}$ as a catalyst for photoredox processes from unactivated aryl and alkyl halides and its usefulness in radical cyclizations, we next focused on a challenging transformation of great synthetic importance: the direct $\mathrm{C}-\mathrm{H}$ arylation of arenes with aryl halides. Besides dehydrogenative cross-coupling processes in which two $\mathrm{C}\left(\mathrm{sp}^{2}\right)-\mathrm{H}$ bonds are simultaneously activated to form biaryl derivatives, the main challenges being to suppress the homocouplings and to control the regioselectivity, the direct $\mathrm{C}-\mathrm{H}$ arylation of arenes indeed represents one of the most attractive route to biaryls. ${ }^{[26]}$ Several photoredox processes have been reported lately for this transformation, most of them relying on activated arylating agents such as diazonium salts, [27] diaryliodonium triflates ${ }^{[28]}$ or arylsulfonyl chlorides. ${ }^{[29]}$ For obvious reasons, aryl halides are more practical and attractive arylating agents that are in addition readily available;

Fig. 5. Coppercatalyzed photoredox direct $\mathrm{C}-\mathrm{H}$ arylation of pyrroles and electron-rich arenes with aryl halides.

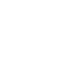


Electron-rich and electron-poor aryl iodides as well as heteroaryl iodides could be used for the arylation and a range of pyrrole derivatives could be efficiently arylated. Notably, the reaction was found to be compatible with a boronate (11i), providing opportunities for further functionalization and diversification, which could be highlighted by an in situ Sonogashira coupling with phenylacetylene and additional palladium tetrakis(triphenylphosphine) (2 $\mathrm{mol} \%)$, and an interesting selectivity was observed starting from 4-bromo-iodobenzene (11e). The arylation could be extended to aryl bromides, provided however that they are activated by an electron-withdrawing group, and electron-rich arenes such as mesitylene, dimethylresorcinol and trimethylphloroglucinol could also be arylated.

As evidenced with all examples overviewed, [(DPEPhos)(bcp)Cu]PF ${ }_{6}$ clearly holds a great potential as a photoredox catalyst applicable to a range of transformations. To further demonstrate its synthetic relevance, it was utilized to promote a key radical domino cyclization to three biologically relevant and/or natural products whose synthesis will be overviewed in the next section.

\section{Application of [Cu(bcp)(DPEPhos)]PF ${ }_{6}$ in Biologically Relevant/Natural Product Synthesis}

Based on the success achieved with the copper-catalyzed radical domino cyclization of suitably functionalized cyanamides and ynamides overviewed above (Fig. 4) and providing a convenient access to complex tetracyclic systems, we indeed briefly studied its extension to the synthesis of natural and/or biologically relevant molecules. We therefore targeted luotonin A 17 ${ }^{[31]}$ and rosettacin 19, ${ }^{[32]}$ respectively natural and synthetic inhibitors of topoisomerase I, an excellent target for cancer chemotherapy ${ }^{[33]}$ due to its crucial role in DNA replication and transcription and its high levels in several human tumors. ${ }^{[34]}$ Because of their combined potential in cancer therapy and their interesting topology, both related targets have stimulated numerous efforts for the development of efficient and modular syntheses. ${ }^{[35]}$ However, limitations still remain, notably in term of flexibility and modularity, two crucial points in a diversity-oriented approach. Based on our studies and inspired by an especially elegant total synthesis of luotonin A by the Malacria group, ${ }^{24 a]}$ we envisioned that the classical tin-based conditions used for the generation of the radical species involved in the key radical cascade cyclization leading to luotonin A might be conveniently replaced by our copper-based photoredox catalyst and visible light (Fig. 6). Cyanamide 16 was therefore readily prepared from precursor $\mathbf{1 5}$ in two steps and submitted to the $[(\mathrm{DPEPhos})(\mathrm{bcp}) \mathrm{Cu}] \mathrm{PF}_{6}$-catalyzed photoredox domino radical cyclization using dicyclohexylisobutylamine and potassium carbonate: a smooth and clean cyclization occurred yielding luotonin A 17 in $79 \%$ yield, a yield that compares nicely to the $43 \%$ yield reported in the Malacria synthesis for the cyclization of the same precursor 16 with $\mathrm{Bu}_{6} \mathrm{Sn}_{2}$ in refluxing toluene under irradiation. [24a] Using a slight modification of the synthetic route, ynamide $\mathbf{1 8}$ could be easily prepared from $\mathbf{1 5}$ in a divergent manner and also underwent an efficient cyclization yielding, after desilylation, rosettacin 19. As an important note, the use of blue LEDs in place of a photoreactor resulted in a similar yield with an increased reaction time (7 days). in three steps from commercially available bromopropylamine hydrobromide 20. Here again, these results compare well with the previously reported related radical cyclization to deoxyvasicinone $\mathbf{2 2}$ of a $N$-benzoyl- $N$-phenylselenopropylcyanamide with tributyltin hydride and AIBN in benzene. ${ }^{[37 n]}$

\section{Insights into the Photocatalytic Cycle Involved with [(DPEPhos)(bcp)Cu]PF}

To have a better understanding of the parameters accounting for the remarkable activity of [(DPEPhos)(bcp)Cu]PF, we next initiated a detailed study of its photophysical properties. As mentioned above, its stability was evaluated by monitoring the UV-visible absorption and by ${ }^{1} \mathrm{H}$ NMR analyses in $\mathrm{CD}_{3} \mathrm{CN}$. While this complex was found to be perfectly stable for 24

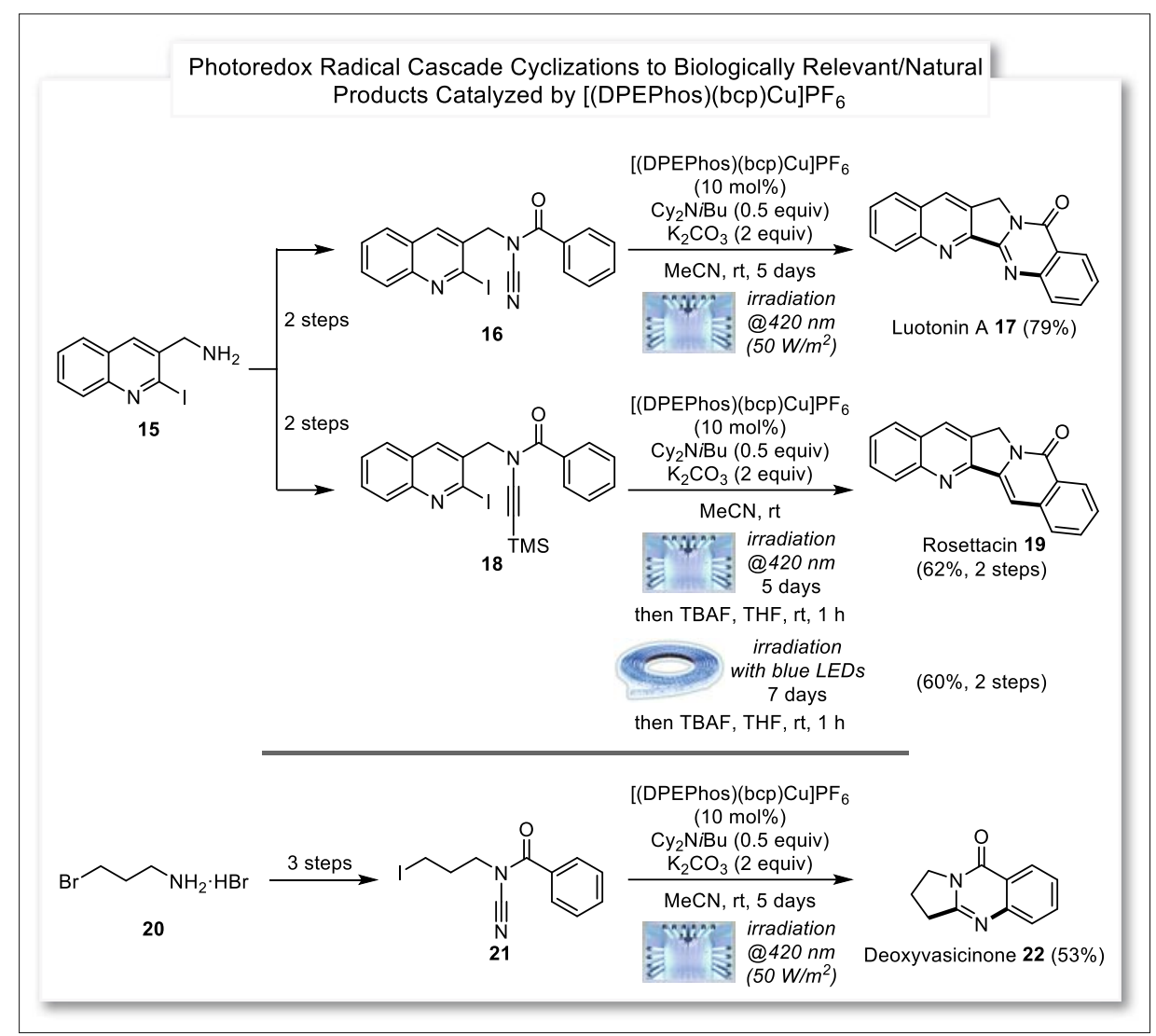

Fig. 6. Application of [(DPEPhos)(bcp)Cu]PF ${ }_{6}$ in biologically relevant/natural product synthesis.

Having previously demonstrated the ability of $[(\mathrm{DPEPhos})(\mathrm{bcp}) \mathrm{Cu}] \mathrm{PF}_{6}$ to activate $\mathrm{C}\left(\mathrm{sp}^{3}\right)-\mathrm{I}$ bonds, this approach could then be extended to the total synthesis of deoxyvasicinone 22, ${ }^{[36,37]}$ a naturally occurring tricyclic quinazolinone that has been reported to possess antimicrobial, anti-inflammatory and antidepressant activities $^{[38]}$ that could be obtained by a photoinduced radical domino cyclization from cyanamide 21, itself prepared hours in the dark, the formation of homoleptic [(bcp) $\left.{ }_{2} \mathrm{Cu}\right] \mathrm{PF}_{6}$ was slowly observed upon irradiation. While the homoleptic complexes were shown to be catalytically inactive, this slow dissociation might account for the relatively high catalytic loading needed in some cases.

The photophysical studies of [(DPEPhos)(bcp)Cu]PF first indicated a luminescence lifetime of $819 \mathrm{~ns}$, which is in the high range for a heteroleptic cop- 
per complex and definitely contributes to its efficiency as a catalyst. An oxidation potential in the excited state of $-1.02 \mathrm{~V}$ vs SCE (estimated from $\mathrm{E}_{1 / 2}\left(\mathrm{Cu}^{\mathrm{II}} / \mathrm{Cu}^{\mathrm{I}}\right)=+1.25$ $\mathrm{V} v s \mathrm{SCE}$ and $\lambda_{\max }^{e m}=546 \mathrm{~nm}$ ) was determined, which is in agreement with recently reported values. ${ }^{[21 b]}$ This value is clearly not in accordance with a $\mathrm{Cu}(\mathrm{I}) / \mathrm{Cu}(\mathrm{I}) * / \mathrm{Cu}$ (II) oxidative quenching cycle (Fig. 7, bottom), the excited copper catalyst being unable to reduce an organic halide. An unusual and rare $\mathrm{Cu}(\mathrm{I}) / \mathrm{Cu}(\mathrm{I}) * / \mathrm{Cu}(0)$ catalytic cycle ${ }^{[39]}$ (Fig. 7, top) would then be operative: the reaction would be initiated by reduction of $[(\mathrm{DPEPhos})(\mathrm{bcp}) \mathrm{Cu}] \mathrm{PF}_{6}{ }^{*}$ with the sacrificial reductant, $i \mathrm{Pr}_{2} \mathrm{NEt}$, an elementary step which is supported by the reduction potential in the excited state for this complex of $+0.63 \mathrm{~V} v s \mathrm{SCE}$ (estimated from $\mathrm{E}_{1 / 2}$

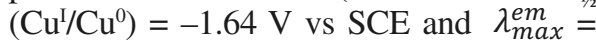
$546 \mathrm{~nm})$ and by the reported oxidation potential of $i \operatorname{Pr}_{2} \mathrm{NEt}\left(+0.68 \mathrm{~V}\right.$ vs SCE). ${ }^{[40]} \mathrm{A}$ transient copper(0) complex [(DPEPhos) (bcp) $\mathrm{Cu}],{ }^{[41]}$ whose oxidation potential was measured to be $-1.64 \mathrm{~V} v s \mathrm{SCE}$, would then be generated and this species would reduce the organic halide $\mathrm{R}-\mathrm{X}$ by single electron transfer, regenerating the copper(I) catalyst and initiating the generation of a radical R', and its further cyclization to R' in the presence of a suitably placed functional group, these radicals being finally reduced by the amine radical cation to afford the final product. In the case of the direct arylation of arenes and radical domino cyclizations, a reductant is not formally needed since the last step corresponds to a reduction of the radical generated after radical addition to the arene followed by rearomatization. This final reduction can be performed by either the amine radical cation or [(DPEPhos) (bcp)Cu]PF *: in the latter case, a substoichiometric amount of the amine is sufficient for the reaction to occur.

While the intermediacy of a rare copper(0) complex (or a copper(I) complex with a reduced ligand) might seem counterintuitive, the formation of copper nanoparticles or copper mirrors in the presence of unreactive organic halides and the strong quenching of $[(\mathrm{DPEPhos})(\mathrm{bcp}) \mathrm{Cu}] \mathrm{PF}_{6} *$ by $i \operatorname{Pr}_{2} \mathrm{NEt}$ observed $\left(\mathrm{k}_{\mathrm{q}}=3.4 * 10^{7} \mathrm{M}^{-1} \cdot \mathrm{s}^{-1}\right.$, Fig. 7) strongly supports this elementary step. The limited quenching of [(DPEPhos) (bcp)Cu]PF ${ }_{6}^{*}$ by iodobenzene $\left(\mathrm{k}_{\mathrm{q}}=6.9 * 10^{6}\right.$ $\left.\mathrm{M}^{-1} \cdot \mathrm{s}^{-1}\right)$ and the inactivity of [(bcp) $\left.)_{2} \mathrm{Cu}\right] \mathrm{PF}_{6}$ also support this mechanism: with a reduction potential in the excited state of -0.02 $\mathrm{V}$ vs $\mathrm{SCE},{ }^{[42]}$ this compound is indeed unable to oxidize $i \operatorname{Pr}_{2} \mathrm{NEt}$.

\section{Conclusions and Outlook}

In conclusion, we have shown that [(DPEPhos)(bcp)Cu]PF $\mathrm{PF}_{6}$ a general and broadly applicable copper catalyst en-

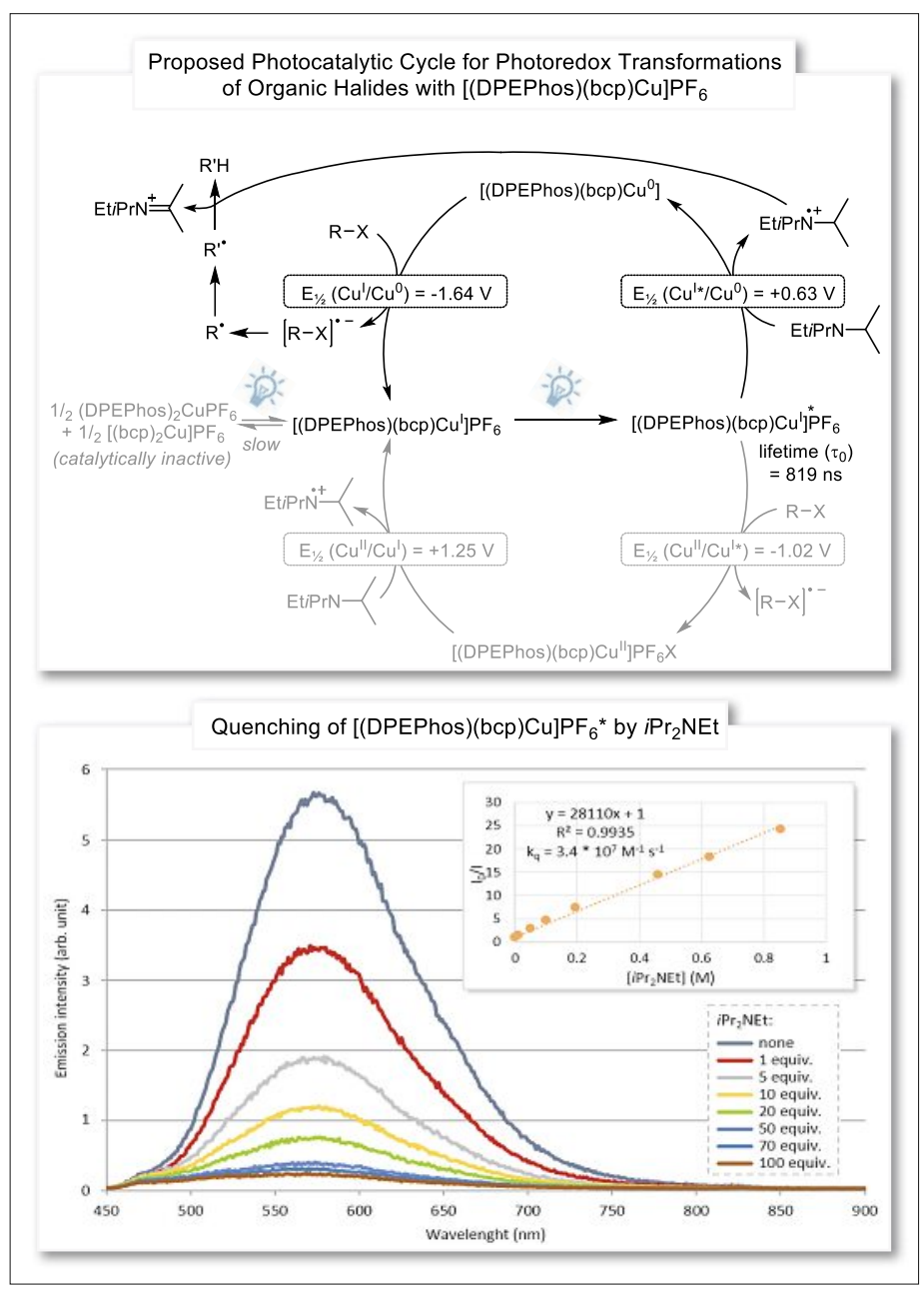

Fig. 7. Proposed photocatalytic cycle for photoredox transformations of organic halides with [(DPEPhos)(bcp)Cu] $\mathrm{PF}_{6}$

abling a wide range of photoredox transformations of organic halides. Both aryl and alkyl halides are readily transformed to the corresponding radicals upon reaction with catalytic amounts of this heteroleptic complex in the presence of a sacrificial electron donor. Besides providing an excellent (and cheaper) alternative to photocatalysis with iridium and ruthenium complexes, as evidenced by a simple comparative analysis with main metal-based photoredox catalysts (Fig. 8) that speaks for itself, this opens new perspectives in the use of copper complexes for photoredox transformations. A rare $\mathrm{Cu}(\mathrm{I}) / \mathrm{Cu}(\mathrm{I})^{*} /$ $\mathrm{Cu}(0)$ reductive quenching photocatalytic cycle has been in addition shown to be involved with this unique photocatalyst, which should pave the way for the development of other, more efficient copperbased photoredox catalysts.

[(DPEPhos)(bcp)Cu]PF 6 is indeed not yet an ideal photoredox catalyst: alternative ones with increased lifetimes in their excited states and higher redox potentials should be developed. The $\mathrm{Cu}(\mathrm{I}) / \mathrm{Cu}(\mathrm{I}) * / \mathrm{Cu}(0)$ catalytic cycle is of major importance in this perspective since it allows circumventing the main problem met with most copperbased photoredox catalysts for which the $\mathrm{Cu}(\mathrm{I}) / \mathrm{Cu}(\mathrm{I}) * / \mathrm{Cu}(\mathrm{II})$ catalytic cycle typically involved is associated with flattening distor- tions and the easy addition of a nucleophile to copper(II) species. Elucidating the exact nature of the transient copper(0) species (i.e. copper(0) or monoreduced copper(I) complexes) will also be of crucial importance, notably for the design of improved photoredox catalysts with non-innocent ligands.

\section{Acknowledgements}

Our work was supported by the Université libre de Bruxelles (ULB), the Fédération Wallonie-Bruxelles (ARC Consolidator 20142019), the FNRS (notably through the grants UN02715F and CDR.J0022.18), and the COST action CM1202. C.D., H.B. and S.K. acknowledge the Fonds pour la formation à la Recherche dans l'Industrie et dans l'Agriculture (F.R.I.A.) for graduate fellowships.

Received: June 18, 2018

[1] For a recent book, see: R. Ameta, S. C. Ameta, 'Photocatalysis: Principles and Applications', CRC Press, Boca Raton, 2017

[2] J. Plotnikow, 'Allgemeine Photochemie', de Gruyter, Berlin, 1936.

[3] A. Fujishima, K. Honda, Nature 1972, 238, 37.

[4] a) C. Pac, M. Ihama, M. Yasuda, Y. Miyauchi, H. Sakurai, J. Am. Chem. Soc. 1981, 103, 6495 b) H. Cano-Yelo, A. Deronzier, J. Chem. Soc., Perkin Trans 2 1984, 1093.

[5] For a recent review, see: I. Roger, M. A. Shipman, M. D. Symes, Nat. Rev. Chem. 2017, 1, 3. 


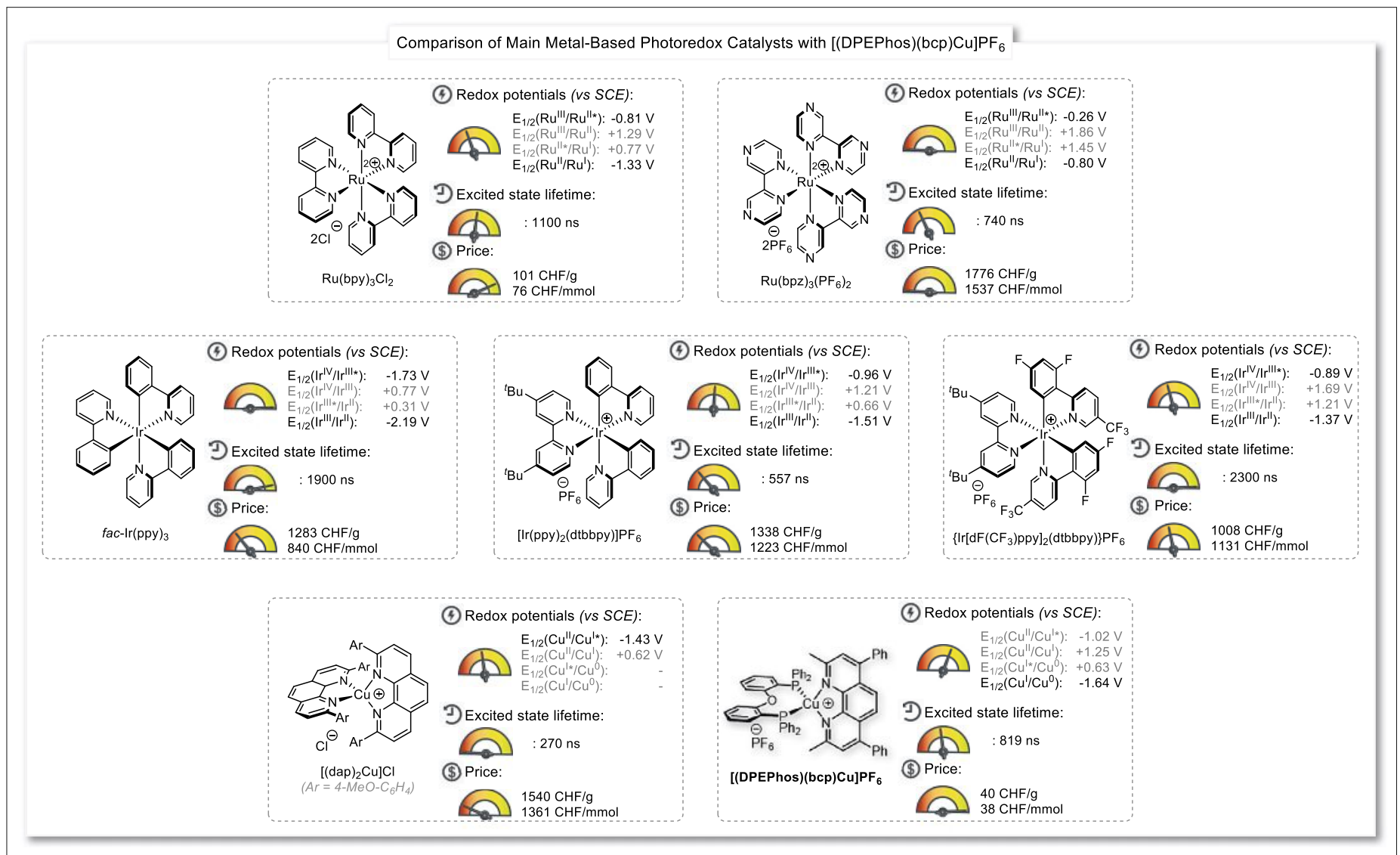

Fig. 8. Comparison of main metal-based photoredox catalysts with [(DPEPhos)(bcp)Cu]PF ${ }_{6}$ (redox potentials indicated in black correspond to elementary steps involving reduction of an organic substrate).

[6] For a recent review, see: S. N. Habisreutinger, L. Schmidt-Mende, J. K. Stolarczyk, Angew. Chem. Int. Ed. 2013, 52, 7372.

[7] For a recent review, see: C. K. Prier, D. A. Rankic, D. W. C. MacMillan, Chem. Rev. 2013 $113,5322$.

[8] N. A. Romero, D. A. Nicewicz, Chem. Rev. 2016, 116, 10075.

[9] For leading examples, see: a) G. Revol, T. McCallum, M. Morin, F. Gagosz, L. Barriault, Angew. Chem. Int. Ed. 2013, 52, 13342; b) T. McCallum, L. Barriault, Chem. Sci. 2016, 7 , 4754.

[10] For reviews, see: a) S. Paria, O. Reiser, ChemCatChem 2014, 6, 2477; b) O. Reiser, Acc. Chem. Res. 2016, 49, 1990.

[11] D. R. McMillin, M. T. Buckner, B. T. Ahn, Inorg. Chem. 1977, 16, 943.

[12] P. A. Grutsch, C. Kutal, J. Am. Chem. Soc. 1979, $101,4228$.

[13] M. Mitani, I. Kato, K. Koyama, J. Am. Chem. Soc. 1983, 105, 6719.

[14] J.-M. Kern, J.-P. Sauvage, J. Chem. Soc., Chem. Commun. 1987, 546.

[15] For general references, see: a) N. Armaroli, Chem. Soc. Rev. 2001, 30, 113; b) N. Armaroli, G. Accorsi, F. Cardinali, A. Listorti, in 'Photochemistry and Photophysics of Coordination Compounds I', Eds. V. Balzani, S Campagna, Springer: Berlin, 2007, pp. 69-115; c) M. S. Lazorski, F. N. Castellano, Polyhedron 2014, $82,57$.

[16] For representative exemples, see: a) S. E. Creutz, K. J. Lotito, G. C. Fu, J. C. Peters, Science 2012, 338, 647; b) M. Pirtsch, S. Paria, T. Matsuno, H. Isobe, O. Reiser, Chem. Eur. J. 2012, 18, 7336; c) A. C. Hernandez-Perez, A. Vlassova, S. K. Collins, Org. Lett. 2012, 14 2988; d) S.-P. Luo, E. Meja, A. Friedrich, A. Pazidis, H. Junge, A.-E. Surkus, R. Jackstell, S. Denurra, S. Gladiali, S. Lochbrunner, M.
Beller, Angew. Chem. Int. Ed. 2013, 52, 419; e) A. C. Hernandez-Perez, S. K. Collins, Angew. Chem. Int. Ed. 2013, 52, 12696; f) C. Uyeda, Y. Tan, G. C. Fu, J. C. Peters, J. Am. Chem. Soc. 2013, 135, 9548; g) D. T. Ziegler, J. Choi, J. M. Muñoz-Molina, A. C. Bissember, J. C. Peters, G. C. Fu, J. Am. Chem. Soc. 2013, 135 , 13107; h) R. S. Khnayzer, C. E. McCusker, B. S. Olaiya, F. N. Castellano, J. Am. Chem. Soc. 2013, 135, 14068; i) A. Baralle, L. Fensterbank, J. P. Goddard, C. Ollivier, Chem Eur. J. 2013, 19, 10809; j) S. H. Oh, Y. R. Malpani, N. Ha, Y.-S. Jung, S. B. Han, Org. Lett. 2014, 16, 1310; k) M. Knorn, T. Rawner, R. Czerwieniec, O. Reiser, ACS Catal. 2015, 5, 5186; 1) X.-J. Tang, W. R. Dolbier, Jr., Angew. Chem. Int. Ed. 2015, 54, 4246; m) D. B. Bagal, G. Kachkovskyi, M. Knorn, T. Rawner, B M. Bhanage, O. Reiser, Angew. Chem. Int. Ed. 2015, 54, 6999; n) G. Fumagalli, P. T. G. Rabet, S. Boyd, M. F. Greaney, Angew. Chem. Int. Ed. 2015, 54, 11481; o) M. Fu, L. Chen, Y. Jiang, Z.-X. Jiang, Z. Yang, Org. Lett. 2016 18, 348; p) S. K. Pagire, S. Paria, O. Reiser, Org. Lett. 2016, 18, 2106; q) Q. M. Kainz, C. D. Matier, A. Bartoszewicz, S. L. Zultanski, J. C. Peters, G. C. Fu, Science 2016, 351, 681.

[17] For representative contributions from our group on copper catalysis, see: a) M. Toumi, F. Couty, G. Evano, Angew. Chem. Int. Ed. 2007, 46, 572; b) A. Coste, M. Toumi, K. Wright, V. Razafimahaléo, F. Couty, J. Marrot, G. Evano, Org. Lett. 2008, 10, 3841; c) A. Coste, F. Couty, G. Evano, Org. Lett. 2009, 11, 4454; d) A. Coste, G. Karthikeyan, F. Couty, G. Evano, Angew. Chem. Int. Ed. 2009, 48, 4381; e) K. Jouvin, F. Couty, G. Evano, Org. Lett. 2010, 12, 3272; f) K. Tadiparthi, F. Couty, G. Evano, Chem. Commun. 2011, 47, 179; g) K. Jouvin, A. Bayle, F. Legrand, G. Evano, Org. Lett. 2012, 14, 1652; h) A. Laouiti, M. M.
Rammah, M. B. Rammah, J. Marrot, F. Couty, G. Evano, Org. Lett. 2012, 14, 6; i) A. Pradal, G. Evano, Chem. Commun. 2014, 50, 11907; j) C. S. Demmer, E. Benoit, G. Evano, Org. Lett. 2016, 18, 1438; k) A. Nitelet, G. Evano, Org. Lett. 2016, 18, 1904; 1) J. Wang, G. Evano, Org. Lett. 2016, 18, 3542; m) C. Theunissen, J. Wang, G. Evano, Chem. Sci. 2017, 8, 3465; n) A. Nitelet, J. Wouters, D. F. Dewez, G. Evano, Org. Lett. 2017, 19, 6276.

[18] B. Michelet, C. Deldaele, S. Kajouj, C. Moucheron, G. Evano, Org. Lett. 2017, 19, 3576.

[19] H. Baguia, C. Deldaele, E. Romero, B. Michelet, G. Evano, Synthesis 2018, 50, 3022

[20] A. C. Hernandez-Perez, S. K. Collins, Acc. Chem. Res. 2016, 49, 1557.

[21] a) D. G. Cuttel, S.-M. Kuang, P. E. Fanwick, D. R. McMillin, R. A. Walton, J. Am. Chem. Soc. 2002, 124, 6; b) H. Takeda, K. Ohashi, A. Sekine, O. Ishitani, J. Am. Chem. Soc. 2016, $138,4354$.

[22] For the catalytic photoredox reduction of aryl halides, see: a) J. D. Nguyen, E. M. D'Amato, J. M. R. Narayanam, C. R. J. Stephenson, Nat. Chem. 2012, 4, 854; b) H. Kim, C. Lee, Angew. Chem. Int. Ed. 2012, 51, 12303; c) I. Ghosh, T. Ghosh, J. I. Bardagi, B. König, Science 2014, 364,725 ; d) E. H. Discekici, N. J. Treat, S. O. Poelma, K. M. Mattson, Z. M. Hudson, Y. D. Luo, C. J. Hawker, J. R. de Alaniz, Chem. Commun. 2015, 51, 11705.

[23] C. Costentin, M. Robert, J.-M. Savéant, J. Am. Chem. Soc. 2004, 126, 16051

[24] a) A. Servais, M. Azzouz, D. Lopes, C. Courillon, M. Malacria, Angew. Chem. Int. Ed. 2007, 46, 576; b) F. Marion, C. Courillon, M. Malacria, Org. Lett. 2003, 5, 5095.

[25] Y.-Y. Han, H. Jiang, R. Wang, S. Yu, J. Org. Chem. 2016, 81, 7276

[26] a) I. Ghosh, L. Marzo, A. Das, R. Shaikh, B. König, Acc. Chem. Res. 2016, 49, 1566; b) O. 
Boubertakh, J.-P. Goddard, Eur. J. Org. Chem. 2017, 2072.

[27] a) D. Prasad Hari, P. Schroll, B. König, J. Am. Chem. Soc. 2012, 134, 2958; b) D. Xue, Z.-H Jia, C.-J. Zhao, Y.-Y. Zhang, C. Wang, J. Xiao, Chem. Eur. J. 2014, 20, 2960; c) J. Zoller, D. C. Fabry, M. Rueping, ACS Catal. 2015, 5, 3900; d) F. Gomes, V. Narbonne, F. Blanchard, G. Maestri, M. Malacria, Org. Chem. Front. 2015, 2, 464.

[28] Y.-X. Liua, D. Xue, J.-D. Wanga, C.-J. Zhaoa, Q.-Z. Zoua, C. Wanga, J. Xiao, Synlett 2013, 24, 507.

[29] P. Natarajan, A. Bala, S. K. Mehta, K. K. Bhasin, Tetrahedron 2016, 72, 2521.

[30] a) Y. Cheng, X. Gu, P. Li, Org. Lett. 2013, 15 , 2664; b) L. Marzo, I. Ghosh, F. Esteban, B. König, ACS Catal. 2016, 6, 6780; c) I. Ghosh, B. König, Angew. Chem. Int. Ed. 2016, 55, 7676; d) A. Arora, J. D. Weaver, Org. Lett. 2016, 18, 3996.

[31] Z.-Z. Ma, Y. Hano, T. Nomura, Y.-J. Chen, Heterocycles 1997, 46, 541.

[32] a) B. M. Fox, X. Xiao, S. Antony, G. Kohlhagen, Y. Pommier, B. L. Staker, L. Stewart, M. Cushman, J. Med. Chem. 2003, 46, 3275. b) K. Cheng, N. J. Rahier, B. M. Eisenhauer, R. Gao, S. J. Thomas, S. M. Hecht, J. Am. Chem. Soc 2005, 127, 838 .

[33] a) C. Bailly, Curr. Med. Chem. 2000, 7, 39. b) L.-H. Meng, Y.-Z. Liao, Y. Pommier, Curr. Top. Med. Chem. 2003, 3, 305; c) Y. Pommier, Nat Rev. Cancer. 2006, 6, 789.

[34] I. Husain, J. L. Mohler, H. F. Seigler, J. M. Besterman, Cancer. Res. 1994, 54, 539.

[35] For total syntheses of luotonin A, see: a) J. L. Liang, H. C. Cha, Y. Jahng, Molecules 2011,
16, 4861; b) H. Wang, A. Ganesan, Tetrahedron Lett. 1998, 39, 9097; c) Z.-Z. Ma, Y. Hano, T. Nomura, Y.-J. Chen, Heterocycles 1999, 51, 1593; d) T. R. Kelly, S. Chamberland, R. A. Silva, Tetrahedron Lett. 1999, 40, 2723; e) T. Harayama, A. Hori, G. Serban, Y. Morikami, T. Matsumoto, H. Abe, Y. Takeuchi, Tetrahedron 2004, 60, 10645; f) W. R. Bowman, M. R. J. Elsegood, T. Stein, G. W. Weaver, Org. Biomol. Chem. 2007, 5, 103; g) Y. Ju, F. Liu, C. Li, Org. Lett. 2009, 11, 3582; also see ref. [24a]. For total syntheses of rosettacin, see: h) M. Shamma, L. Novak, Tetrahedron 1969, 25, 2275; i) E. J. Corey, D. N. Crouse, J. E. Anderson, J. Org. Chem. 1975, 40, 2140; j) F. Pin, S. Comesse, M. Sanselme, A. Daïch, J. Org. Chem. 2008, 73, 1975; k) X. Xu, Y. Liu, C. M. Park, Angew. Chem. Int. Ed. 2012, 51, 9372; 1) L. Song, G. Tian, Y. He, E. Van der Eycken, Chem. Commun. 2017, 53, 12394; m) C. R. Reddy, K. Mallesh, Org. Lett. 2018, 20, 150; n) L. El Blidi, A. Namoune, A. Bridoux, V. D. Nimbarte, A. M. Lawson, S. Comesse, A. Daïch, Synthesis 2015, 47, 3583; o) K. Li, J. Ou, S. Gao, Angew. Chem. Int. Ed. 2016, 55, 14778.

[36] A. H. Amin, D. R. Mehta, Nature 1959, 183, 1317.

[37] For representative syntheses of deoxyvasicinone, see: a) M. Mori, H. Kobayashi, M. Kimura, Y. Ban, Heterocycles 1985, 23, 2803; b) H. Takeuchi, S. Hagiwara, S. Eguchi, Tetrahedron 1989, 45, 6375; c) M. Akazome, T. Kondo, Y. Watanabe, J. Org. Chem. 1993, 58, 310; d) M. Mori, H. Kobayashi, M. Kimura, Y. Ban, Heterocycles 1997, 46, 541; e) S. B. Mhaske, N. P. Argade, J. Org. Chem. 2001, 66, 9038; f) E.
S. Lee, J.-G. Park, Y. Jahng, Tetrahedron Lett. 2003, 44, 1883; g) J.-F. Liu, P. Ye, K. Sprague, K. Sargent, D. Yohannes, C. M. Baldino, C. J. Wilson, S.-C. Ng, Org. Lett. 2005, 7, 3363; h) C. Gil, S. Bräse, Chem. Eur. J. 2005, 11, 2680; i) A. Hamid, A. Elomri, A. Daïch, Tetrahedron Lett. 2006, 47, 1777; j) W. R. Bowman, M. R. J. Elsegood, T. Stein, G. W. Weaver, Org. Biomol. Chem. 2007, 5, 103; k) T. M. Potewar, S. A. Ingale, K. V. Srinivasan, ARKIVOC 2008, XIV, $100 ; 1)$ C. Zhang, C. K. De, R. Mal, D. Seidel, J. Am. Chem. Soc. 2008, 130, 416; m) J. Fang, J. Zhou, Org. Biomol. Chem. 2012, 10, 2389; n) M.-H. Larraufie, M. Malacria, C. Courillon, C. Ollivier, L. Fensterbank, E. Lacôte, Tetrahedron 2013, 69, 7699.

[38] A. Al-Shamma, S. Drake, D. L. Flynn, L. A Mitscher, Y. H. Park, G. S. R. Rao, A. Simpson, J. K. Swayze, T. Veysoglu, S. T. S. Wu, J. Nat. Prod. 1981, 44, 745.

[39] B. Wang, D. P. Shelar, X. Z. Han, T. T. Li, X. G. Guan, W. Lu, K. Liu, Y. Chen, W. F. Fu, C. M. Che, Chem. Eur. J. 2015, 21, 1184.

[40] U. Pischel, X. Zhang, B. Hellrung, E. Haselbach, P.-A. Muller, W. M. Nau, J. Am. Chem. Soc. 2000, 122, 2027.

[41] For rare examples of copper(0) complexes, see: a) K. L. Cunningham, D. R. McMillin, Inorg. Chem. 1998, 37, 4114; b) D. S. Weinberger, N. A. SK, K. C. Mondal, M. Melaimi, G. Bertrand, A. C. Stückl, H. W. Roesky, B. Dittrich, S. Demeshko, B. Schwederski, W. Kaim, P. Jerabek, G. Frenking, J. Am. Chem. Soc. 2014 136,6235 .

[42] K. Karlsson, C. Moucheron, A. Kirsch-De Mesmaeker, New J. Chem. 1994, 18, 721. 